\title{
FROM THE CEU/NEWS ROUNDUP
}

linear manner during the 'pill-free' week, with concentrations at the end of the week being, on average, approximately two-fold higher than during $\mathrm{COC}$ coadministration. The clinical effects of this were not reported in the study; however, the CEU sought guidance from several physicians/neurologists. All were in agreement that that the degree of fluctuation in lamotrigine levels seen in the 'pill-free' week is unlikely to be of clinical significance. They confirmed that serum levels are unhelpful in predicting therapeutic effects or side effects.

No evidence was found with respect to progestogenonly methods. Moreover, there is no evidence to suggest that lamotrigine is a liver enzyme-inducing drug. Evidence does not support the advice that women using lamotrigine should use only non-hormonal methods.

\section{Evidence reviewed: existing FFPRHC Guidance}

The Faculty of Family Planning and Reproductive Health Care (FFPRHC) have produced a CEU Faculty Statement on the changes to prescribing information for lamotrigine. ${ }^{7}$

\section{Disclaimer}

The advice given in this Member's Enquiry Response has been prepared by the FFPRHC Clinical Effectiveness Unit team. It is based on a structured search and review of published evidence available at the time of preparation. The advice given here should be considered as guidance only. Adherence to it will not ensure a successful outcome in every case and it may not include all acceptable methods of care aimed at achieving the same result. This response has been prepared as a service to FFPRHC members, but is not an official Faculty Guidance product; Faculty Guidance is produced by a different and lengthier process. It is not intended to be construed or to serve as a standard of medical care. Such standards are determined on the basis of all clinical data available for an individual case and are subject to change as scientific knowledge advances. Members are welcome to reproduce this response by photocopying or other means, in order to share the information with colleagues.

References

1 British National Formulary, vol. 49. London, UK: British Medical Association and the Royal Pharmaceutical Society of Great Britain, March 2005. http://www.BNF.org [Accessed 25 August 2005].

2 GlaxoSmithKline UK. GlaxoSmithKline Health Care Update: Lamictal (Lamotrigine). 2005. http://www.gsk.com. [Accessed 25 August 2005].

3 Sabers A, Buchholt JM, Uldall P, Hansen EL. Lamotrigine plasma levels reduced by oral contraceptives. Epilepsy Res 2001; 47: 151-154.

4 Feskanich D, Hunter DJ, Willett WC, Spiegelman D, Stampfer MJ, Speizer FE, et al. Oral contraceptive use and risk of melanoma in premenopausal women. Br J Cancer 1999; 81: 918-923.

5 Sidhu J, Job S, Buisara S, Phillipson R. Pharmacokinetics and Hormonal Effects of Lamotrigine-Combined Oral Contraceptive Coadministration. 2005. http://ctr.gsk.co.uk/Summary/lamotrigine/ 1_LAM10016.pdf [Accessed 25 August 2005].

6 Stodieck SRG, Schwenkhagen AM. Lamotrigine (Letter). Epilepsia 2004; 45(Suppl. 7)

7 Faculty of Family Planning and Reproductive Health Care Clinical Effectiveness Unit. Faculty Statement from the CEU on Changes to Prescribing Information for Lamotrigine. 2005. http://www. ffprhc.org.uk/admin/uploads/lamotrigine.pdf [Accessed 24 October 2005].

\section{News Roundup}

\section{Reporting of sexually active young teenagers}

In the wake of the Bichard enquiry, a review of the current guidance, Working Together to Safeguard Children, is taking place. It is due to be published in January 2006 but it seems there is already some confusion regarding reporting of underage sex. Child protection committees have already issued guidance which conflicts with the current Department of Health advice. Presently the Department of Health recognises that children younger than 16 years have rights to confidentiality if considered competent. However, Sheffield and London child protection committees have produced protocols that compel health professionals to report all sexual activity in young people under the age of 13 years, similar to the situation in the USA and some states in Australia. In a country with the highest teenage pregnancy rate in Europe, I wonder how teenagers will view this new guidance, and how it will affect vulnerable teenagers in our society.

\section{Reference \\ Bastable R, Sheather J. Mandatory reporting to the police of} all sexually active under-13s. BMJ 2005; 331: 918-919.

Reported by Laura Patterson, MRCGP, DFFP $G P$, Cirencester, $U K$

\section{Tackling chlamydia}

A team of scientists at the University of Cambridge has developed a new test for chlamydia. It is simple to use, cheap, takes less than 25 minutes to give a result and can be used with non-invasive samples. At present a performance evaluation study is being undertaken at Brook in Birmingham, UK. Following this it will be licensed and made available for use by health professionals. Preliminary testing results are looking very encouraging. Boots the Chemist are also attempting to make chlamydia testing accessible. From November 2005, branches of Boots the Chemist across London, UK will undertake a pilot programme offering testing and treating of chlamydia. This is another valuable tool to complement the continuing development of the national screening programme.

Source: Department of Health

Reported by Laura Patterson, MRCGP, DFFP GP, Cirencester, UK

\section{NICE guidance for LARC}

The National Institute for Health and Clinical Excellence (NICE) guideline for long-acting reversible contraception (LARC) is 40 pages in length. It sets clear guidance for the use of the four methods of LARC available in the UK, namely copper intrauterine devices (IUDs), the intrauterine system (IUS), progesterone-only injectable contraception and progesterone-only subdermal implants. However, it does remind us that most of the evidence is extrapolated, as there is little available robust evidence in this area. It reminds us about good communication and encourages us to help women make an informed choice about their contraception. At present the uptake of these forms of contraception is low. However, LARC could reduce the rate of unplanned pregnancies. Bearing in mind that these methods are more cost effective than the combined oral contraceptive at 1 year, this document is a valuable reminder to health care professionals guiding women in their choice.

The individual sections of guidance are pretty much as one would expect. I was, however, surprised by the quoted figures cited for discontinuation rates. Up to $50 \%$ of women stop using IUDs within 5 years, most commonly because of unacceptable vaginal bleeding and pain. Up to $60 \%$ of women stop using the IUS within 5 years, again because of unacceptable vaginal bleeding and pain. Up to $50 \%$ of women stop using depot medroxyprogesterone acetate
(DMPA) for reasons of altered bleeding pattern. This clearly emphasises the importance of giving clear information and helping women make an informed choice.

Without robust evidence, NICE indicate that DMPA may be given up to 2 weeks late without the need for additional contraceptives. This is outside the licensed indications. It also makes reference to the use of the subdermal implant Implanon ${ }^{\circledR}$ in women weighing over $70 \mathrm{~kg}$. However, there is no recommendation as to whether there may be reduced effectiveness in the final year of use in this group.

The guidance is due for review in 4 years' time but I am sure will provide an extremely useful reference for health professionals.

Source: www.nice.org.uk

Reported by Laura Patterson, MRCGP, DFFP GP, Cirencester, UK

\section{Sex education in the USA}

There is a substantial federal budget available in the USA for sex education. Several states recently have rejected this money for fear that the education they are now expected to provide has become very restrictive. Since 1996, the state of Maine has been using 'a comprehensive approach to family life' education. Through this they have achieved a steep decline in teenage pregnancies and in the rate of terminations. However, the federal programme now requires teachers to advocate abstinence until marriage and mutual faithfulness afterwards rather than comprehensive sex education. They must emphasise that abstinence is the only certain way to avoid pregnancy and sexually transmitted infections.

Reference

Tanne JH. US state rejects deferral funding for abstinence only sex education $B M J 2005 ; 331: 715$.

Reported by Laura Patterson, MRCGP, DFFP GP, Cirencester, UK 